\title{
THE SUBSTITUTION OF ELECTRICITY FOR STEAM IN RAILWAY PRACTICE.
}

\author{
BY LOUIS DUNCAN.
}

In an address delivered before this Institute in June, 1892, Mr. Frank J. Sprague spoke of the coming development of electricity as applied to railways, and outlined his views as to the direction of this development. In the last three years great extensions have been made in electrical transportation, and it seems well to review briefly the amount of these extensions and their direction. In this paper I shall consider electric traction as it stands at present and not the possibilities of the future.

In the last seven years electricity has largely taken the place of horses for tramway work, and it is now beginning to replace cables, although the latter have been recently installed at great expense. At first the lines were confined to the limits of towns and cities, but they have been extended first into the suburbs, and then to neighboring towns, and the extensions have brought them in competition with the steam roads. The reports of the earnings of the railroad companies in the United States show that after paying fixed charges only a small amount of the net profit remains to be applied to dividends on the stock. Any general decrease in the earnings, even if it is only a small percentage of the total amount, will wipe out the narrow margin that is now applied to dividends, and the absorption by the electrical lines of the local travel formerly conducted by the steam lines promises to do this. At first the managers of the larger steam roads ignored the growth of their electrical rivals, but the time has come when they can no longer ignore the decrease in the 
receipts from their local passenger travel, and they are beginning to face the difficulty and to carefully study the situation.

In this paper I will briefly take up the following questions:

1. Given a railroad system at present operated by steam; will it pay to change entirely to electricity, or to make a partial substitution, and how should the change be made?

2. If entirely new lines are to be built, is it likely that it will pay to equip them electrically, and how should they be equipped?

3. I will describe the equipment of the Baltimore and Ohio tunnel plant and draw from it what morals I can.

In order that it should pay a railroad to make a change in its motive power, the effect of the change must be either to increase the receipts or decrease the expenses by an amount equal to the interest on the first cost of the change. That is, there should theoretically be such a gain ; practically, the amount should be greater in order to justify the change, to take in to account those elements not capable of exact calculation, and also the fact that an increase in the fixed charges of a road is a more serious matter than the mere amount of it, for although the average for a number of years might show a gain by the substitution of electricity in a bad year the increased fixed charge might cause difficulty.

There are two very distinct sides to the question of transportation, the passenger side and the freight side, and their requirements for good service are very different.

First, taking up the question of passenger travel. The receipts of a road are increased by running trains at short intervals and at high speeds, and this is a condition peculiarly favorable to electricity. On an electric line, short trains equally distributed over the track give a greater station efficiency, and the lowest cost of equipment of both station and line. The cost of train service is somewhat greater, but is compensated by the saving in the other items.

The cost of hauling a given number of passengers between given points by steam is greatly increased when the number of trains is increased. The efficiency is less, and the cost of equipment and of train service is greater. Wellington states that doubling the number of engines for a given traffic increases the cost of transportation about 50 per cent.

On the other hand, if we take up the question of freight traffic, the conditions of greatest economy are reached when trains of a maximum weight are hauled by a single locomotive. The 
tendency in late years has been in the direction of increasing the size of the locomotive, the capacity of the cars and the length of the trains. These changes have necessitated more solid and expensive road beds, heavier rails and general strengthening of bridges. The outlay has been enormous, but the decreased cost per ton mile for freight transportation has shown the wisdom of the change. On one of the larger roads which publishes careful yearly statistics, I find that the cost of transportation per ton mile in 1870 was 1.15 cent, and in 1890.56 cent; on another road it was 1.9 cent in 1864 and .447 cent in 1893 . The number of tons per train mile on the first roád in 1870 was 103, while in 1890 it was 226 . In attempting to carry on traffic of this kind by electrical locomotives operated from a central station, we find that we are at a great disadvantage because of the irregular service necessitated by the freight traffic and the unequal distribution of the load along the line. Suppose, for instance, that there were two stations supplying the line and that the traffic was uniformly distributed along it, then the capacity of each station would be one-half of the total required capacity. 'Suppose, however, that the entire traffic was concentrated in one train, then each station would have to have a capacity equal to the total power required for hauling the entire traffic, as the train would be first supplied from one station, and then from the other. The line also would have to have a capacity suitable for handling the total traffic. If a number of heavy trains were used, and the traffic was irregular and liable to be congested at one point, as in the case of freight service, then again the capacity of the stations would have to be greater than that required to supply one-half of the normal traffic. If we were to decide to transmit the current to a longer distance and to supply all the track from one station, using transformer devices along the line, then the capacity of the station itself would only be that required for the normal traffic of the line, but the transformer devices would have to be sufficient to handle the maximum traffic of the section which they supplied, and would have to be given a capacity greatly in excess of their average load in order to supply this energy. We must distinctly bear in mind in considering the application of electricity to steam roads, that any departure from a uniform distribution of load along the line will increase both the cost of equipment and the cost of operation.

In looking over the reports of the same road from which I 
have given freight statistics, I find that in 1870 the receipts per passenger mile were 2.09 cents, while the expenses were 1.59 cents. In 1890 the receipts were 1.9 cent, while the expenses were 1.47 cent. During this period the passengers per train mile have decreased from 79 to 59. Comparing these figures with those given for freight transportation, we find that the two types of traffic have gone in opposite directions in the period we have been considering. The amount of freight transported per train mile has more than doubled, and the expense has decreased more than one-half. The passengers per train mile, on the other hand, have decreased, and the expenses have changed only a slight amount, notwithstanding the greater economies that have been put in force in the interval. Passenger traffic has come in the direction in which electricity is the most economical for transportation ; freight traffic, on the other hand, has gone in the direction where electricity becomes most costly. It might be argued that some new scheme for freight transportation by electricity might be used, but it would be difficult to devise any system more economical than that at present in use, and the great amount of through traffic on freight lines precludes the possibility of devising any system which differs radically from that at present in use. For instance, taking the figures from the records of the Pennsylvania Railroad for 1893, I find that the freight mileage of foreign cars on the lines of the Pennsylvania road east of Pittsburg is in round numbers, $370,000,000$, while the freight mileage of home cars is $436,000,000$, making almost 46 per cent. of the total mileage made by foreign cars. It would seem, then, impossible to change the present system of freight traffic without disorganizing the service and decreasing the freight revenue of the road. The importance of freight traffic is shown by the fact that the earnings from freight on all the roads in the United States is between two and one-half and three times as great as that for passenger traffic. The New York Central Railroad Company in 1892 received from their freight traffic $\$ 26,000,000$, and from their passenger traffic $\$ 13,000,000$. On the lines of the Pennsylvania Railroad east of Pittsburg the freight receipts were $\$ 47,000,000$ as against $\$ 17,000,000$ for passenger receipts.

Suppose, then, the question comes up before the managers of a road as to whether they are to equip their lines to be operated entirely by electricity. It seems to me as matters now stand it 
will not pay trunk lines to change the method of operation for freight traffic, and the question to be considered would be the operating of the lines partly by steam and partly by electricity. Let us consider if it is possible to run the passenger service wholly or partly by electricity. Considering a two track road doing a through as well as a local business, I think we can decide that, unless the case be an exceptional one, it will not pay to equip the main line electrically. It is necessary that the through express service be continued and that the freight service be continued, and an attempt to operate the local trains with the through trains could not be successful if there was any considerable amount of through traffic. With a four-track road the condition of affairs is somewhat different. If the road operates between cities acting as terminal.points for all passenger traffic, as with some of the lines between Boston and New York, then by equipping all four tracks it would be possible to run express service at short intervals on two of the tracks, and on the other two tracks to run freight and local trains. At present it would not pay to use electric locomotives operated from a central station for the freight service, but the local service could be operated electrically; and as the speed of the local trains would be approximately equal to that of the freight, there need be no serious interference with the traffic. We would then have express passenger service working under favorable conditions-that is, with a number of trains evenly distributed, a local service operated under similar favorable conditions and with no interruption to the freight traffic. If the road, however, is to transport a considerable number of foreign cars as, for example, the New York Central or the Pennsylvania railroad, then the condition of affairs for express service would not be so favorable, and the question of the equipment of the tracks for express service would have to be carefully considered. As far as the branch lines go, whether it would pay to partially or wholly substitute electricity for steam depends upon the local conditions. A long branch with a small amount of local traffic it would not pay to equip, but on a short branch with considerable passenger traffic and comparatively little freight traffic such equipment would pay. I find that in 1892 the total number of through passengers carried by the New York Central road was 234,650, while the number of local passengers was $21,978,979$. It will be seen that the through traffic is but a small percentage of the total number of passengers, 
and that the question of preserving the local traffic is of great importance. Now the greater part of this local traffic will, in the next few years, be taken by the electric roads paralleling the steam road, unless some effort is made either to control the electric roads or to give an equally good service between adjacent towns. This latter is possible, using the ordinary steam tracks, only when the distances between towns are small, and the amount of freight or through traffic is also small.

There are certain kinds of local traffic which the steam roads must, to a large extent, lose, and which in the nature of things they cannot regain. In large cities having a considerable suburban traffic the trolley roads, forming as they do a network of lines within the city and extending in every direction into the suburbs, offer advantages with which the steam roads cannot compete. In Philadelphia one of the large steam lines lost so much traffic that it has attempted to regain it by reducing prices and increasing the number of trains. In this effort it has partly succeeded, but at the cost of greater expense and decreased receipts. To counterbalance this loss at central points railroads may hope, by the introduction of electricity, to increase their earnings along the lines and on their branches.

As to the nature of the equipment that will be required, it would depend on the work to be done and the branch that is to be equipped. In some cases it might be well to use single electric cars running on the steam tracks between towns, and on the local tram lines in the towns. As the speed would be very different in the town and on the railroad line, and as the voltage could also be different, it would be well in this case to use a number of motors on the car, and to use a series parallel controller, the motors being in series for the town traffic. For instance, suppose we wish to run at a maximum speed of 40 miles per hour between two towns, and it is economical to use 1,000 volts on the line, we could use two motors on the car, run them in parallel on the main line at a speed of 40 miles per hour, while in town, with a voltage of 500 . we could run them in series at a speed of 10 miles per hour. I can hardly imagine a case where the three-wire system could be economically used for such service on the steam lines.

The condition of affairs in electric transportation is at present curious. The trolley companies, by extending their lines, are working from tramway transportation to through transportation. 
They are attacking the problem by development from small motors to larger ones. The railroad companies starting with the large units are coming down in the direction of the present trolley systems, as in the case of the Nantasket Beach road of the New York, New Haven \& Hartford company. Perhaps in the future they will meet, and some standard electrical system will be adopted for the present steam road. I think then, that in the case taken up, the policy of the road will be to equip those branches for which the conditions are favorable, with a trolley, run comparatively large motor cars capable of drawing one or two ordinary passenger or freight cars as trailers, using the present steam service for their freight traffic when necessary. This will allow the necessary through travel, will give the required local service between towns, and will not interfere with the freight traffic.

As for the systems to be used for such services, I believe that at the present moment the continuous current overhead trolley system is the only one that can be selected with a certainty of successful operation. It gives a minimum complication in the way of conveying the current to the cars, it allows a considerable range of speed with a comparatively high efficiency, and our experience with it is such that successful operation could be at once guaranteed. By using different voltages in the towns and on the line, both high and low speeds can be obtained. If the line to be operated is to be very long, it might be best to use rotary transformers at different sub-stations along it, the line being supplied by continuous currents from the sub-stations. In fact, the three systems that are at present possible are: First, the ordinary direct current system ; second, a system in which direct currents are used on the line and rotary transformers supplied by alternating currents are placed along it, and third, a two or threephase system supplying rotary field motors on the cars. In the latter case it would be well to employ different periods in the towns and on the lines.

The second case which I wish to consider, is that of roads built for an entirely new electrical equipment such, for instance, as the elevated roads in Chicago and the underground rapid transit road in New York, or the proposed Washington-Baltimore Boulevard line. In most of these cases the traffic is almost entirely a passenger traffic, and the conditions are especially favorable for the operation of electricity. Taking, first, the case of 
the New York underground road, there will probably be required about 150 trains for local service, each train having five ordinary cars and a motor car. For the express service there would be about 25 trains of, say, four ordinary cars with a motor car. For this it would probably be best to use the direct current threewire system, one of the cars on the train being equipped with motors and acting as a locomotive. With four motors on a car, the system would be efficient at all practical speeds, and if desired, a large part of the energy could be thrown back on the line when the cars are being stopped. In the case of the local trains, a simple calculation will show that a very small part of the total energy expended, is used in overcoming the track resistance, while a very considerable part is employed in accelerating the train and afterward wasted by braking. I have calculated the amount of energy which can be practically saved under the conditions of local and express traffic on the New York underground road, and find that with motors of ordinary efficiency about 45 per cent. can be returned. If storage batteries are used in connection with the central stations, the batteries being located along the line, a uniform load can be thrown on the stations, and their capacity may be reduced to almost one-half, as compared with a system in which the energy is not returned, thus greatly decreasing both the expense of installation and of operation. As it is possible at present to obtain batteries with a rapid discharge rate at very reasonable prices and with a guarantee for repairs, that place them well within the limit of commercial calculations, a system of this kind offers some advantages over any other system that could be applied to the operation of the underground road. An alternating current would hardly be economical for this work, as it precludes the possibility of returning the energy to the line, and as the variable speed required makes it uneconomical as compared with the direct current system using, say, four motors with series parallel control. In the case above cited, shunt motors would be used, and it would be possible to get a contact with the line that could not under any circumstances be broken. The case of the elevated roads is very similar to the one I have cited, except that in existing structures shorter trains would be used, and the cost of equipment for a given number of cars would be somewhat greater.

Baltimore has been the pioneer in almost every branch of transportation. In ocean service, the record of the Baltimore 
clipper is a tradition of our maritime supremacy. The Baltimore \& Ohio railroad was the pioneer steam road. An electric road from Baltimore to Hampden, built in 1885, gives us a right to boast of our pioneer work in electrical tramways. The immense locomotive for the Baltimore Belt Line tunnel is the first instance of the direct displacement of steam by electricity, and the line over which it is to be operated is the first through steam line to be equipped electrically. The Baltimore \& Columbia Railway Company owns in Washington the Eckington and Soldiers' Home Railroad and the Belt Line railroads and has franchises for extensive additions to their present mileage. In Baltimore they are constructing a road in the city and beyond it to Ellicott City, and they have also purchased a steam line running from Baltimore to Catonsville. They have rights of way from the terminus of their Baltimore lines to the lines they own, and are preparing to build in the District of Columbia. The problem offered is not a simple one, but it is one of the most attractive that can be presented to electrical engineers. Speeds of 60 miles per hour are to be used for the cars outside of the city limits, and within the city limits ordinary speed is to be employed. In the District of Columbia, overhead trolley lines are not allowed and some type of conduit will have to be employed. In fact, there is presented almost every problem which must be solved, if electricity is to displace steam in the future with the same rapidity that it has done in the past. Many high-speed electric roads have been projected, a number of them occupying considerable space in the newspapers, but I think this road will be the first to solve the detailed problem of interurban rapid transit.

The last subject which I wish to take up is the electric plant for the Belt Line tunnel of the B. \& O. railroad. In this case there is no question of economy in the employment of the electrical locomotives, as the plant adds considerably to the cost of operating the road. The Belt Line tunnel runs beneath the city of Baltimore for a distance of one and one-quarter miles, then to the outskirts of town through open cuts and short tunnels. There is a grade of .8 of one per cent over almost the entire length of the tunnel proper, while one-half mile beyond it there is a grade of one and one-half per cent. Being in the middle of town it would have been difficult to have provided a satisfactory ventilating plant, even supposing that ventilating 
plants had been successful in other localities, which is not the case. The managers of the B. \& O. Railroad Company wished to provide a satisfactory service, and considered a number of plans for drawing their trains through the tunnel without the annoyance due to smoke and gases. After careful consideration, they concluded that electricity was the most satisfactory means to accomplish this, and the General Electric Company was confident enough of its ability to successfully equip the road to make a contract with the B. \& O. company to haul its trains over the Belt Line, the contract being dependent upon the successful operation of the plant. The total length of the line equipped is about three miles, the extension beyond the tunnel being for the purpose of assisting the freight locomotives to haul their trains up the one and one-half per cent grade on the line beyond the tunnel. There are to be three locomotives, and it is calculated that the traffic can ordinarily be handled by two of them. The steam engines are not to be taken off the train, but hauled through the tunnel by the electric locomotive which switches off at the terminus of the line. To operate these machines, a station has been erected which contains 3,000 horsepower of electric generators, and an overhead line has been equipped to transmit the current to the locomotives. With respect to the station itself, there is little that is novel. There are four 750-horse power Allis-Corliss engines directly coupled to generators of the same capacity, the generators having a voltage of 600 at no load, and 700 at full load. The foundations have been partly erected for a fifth unit in case it is found necessary. The building also contains a lighting plant having a capacity for 400 are lights, and four thousand 16-candle-power incandescent lights. Provision has also been made for an extension to this lighting plant when the stations for the Belt Line are erected. There are two incandescent machines, and one of them will be used to supply the one thousand 32-candle power lamps which have been installed in the tunnel. Perhaps the most novel feature of the plant is the overhead structure that is employed. The conditions to be met were peculiarly difficult, and the ordinary under-running trolley was considered impracticable. The tunnel is very low in places, and the management of the road decided that the conductors could not be placed over the cars, but should be placed in the middle of the tunnel between the tracks. Outside of the tunnel the conductor is still between 
the tracks, but is elevated to a height of 22 feet, while inside of the tunnel it is only 17 feet from the top of the rail. The conductor consists of an iron trough made of two $Z$ bars riveted to a cover plate 12 inches wide, leaving a slot one inch wide between the $Z$ bars. In the tunnel this trough is supported from transverse channel bars secured to expansion bolts which are fastened in the top of the tunnel. There is a double insulation, one porcelain insulator being between the trough and the channel bars, and another between the channel bars and the expansion bolts. Outside the tunnel the trough is supported as follows: At distances of 150 feet, light iron columns with cross trusses are erected, and between these trusses are hung satenaries supplied with a number of suspension bolts. Transverse channels similar to those used in the tunnel are fastened to these bolts, and the trough is fastened to the channels. The $Z$ bars are made in lengths of 30 feet, the opposite bars breaking joints with one another, the lengths being riveted together and then bonded with "Chicago" rail bonds. Suspended on the same transverse beams as the trough, are three copper cables of 1,000,000 circular mils area, which serve as feed wires, and which are connected at intervals with the trough, there being, of course, one trough for each track. For the return circuits the tracks are bonded as in ordinary railroad work, there being cross bonds and at intervals connections with a copper cable of $1,000,000$ circular mils area carried in a wooden trough between the tracks. The contact arrangement that is to be used consists of a brass shoe traveling in the trough, and connected with the locomotive by a flexible saw-buck arrangement which has a very considerable range in every direction. The current is transmitted to the motors by a copper cabie, and in case of the shoe sticking in the trough, a safety pin is arranged to break with any desired strain. Where switches are used, there is a tongue worked by the lever which operates the track switch, and which serves to direct the shoe. This structure, although exceedingly massive and expensive, promises to give an excellent contact at all times, and it requires no care from the motorman.

The locomotives are the most massive in the history of either steam or electrical transportation, and the weight, which amounts to 95 tons, is on eight driving wheels, so that the full tractive power of the locomotive will be developed. On each axle there is sleeved a 6-pole motor, there being considerably play between 
the axle and the sleeve, which latter is spring-supported from the frame. In this way any heavy blow due to irregularities in the track is taken through the springs, and the wear both of the track and locomotive is reduced. On the armature shaft are projecting arms which move between lugs cast on the wheels, thus allowing the necessary relative motion between the axle and armature.

The situation in the Baltimore Belt Line plant is this: The station is completed, and is being operated daily. One of the locomotives is on the ground set up and ready to run, and the overhead work is finished with the exception of a short length which was interfered with by a temporary bridge over a cut. The latter has been removed, and the plant should be ready to run this week.

If this equipment proves successful, it will open a limited but important field for the introduction of large electric locomotives. There are in the United States a number of tunnels whose operation is anything but satisfactory at present, which can be equipped as the Baltimore tunnel is. Not only would the economy of the station be increased, but the substitution of electric for steam switching engines would result in a very considerable saving.

This is the last of the subjects that I proposed to consider. In this paper I have not indulged in prophecy, nor have I imagined any apparatus or equipment which cannot be bought to-day in the open market. But to me it seems that the present is a crisis in the history of railroading. Up to the present the steam roads have ignored the competition of electric roads, or they have fought them. To-day they cannot afford to do either. In a few years electric roads will have absorbed practically all of the local traffic and will begin to cut into through transportation. The steam roads cannot afford this, and their only safety is to make of electricity an ally instead of an enemy, and this before it is too late.

The conclusions that I finally reach are :

1. The tendency of passenger transportation on the steam lines has been in the direction of the greatest electrical econorny, while the tendency of the freight transportation has been in the direction of the least electrical economy.

2. It will not pay any through line with considerable traffic, having two tracks, to equip their main tracks electrically.

3. With four-track roads it will pay to equip all of the tracks 
electrically unless a considerable portion of the business is through passenger traffic.

4. It will pay all the larger roads either to equip a number of their branch lines electrically, or to control competing electric lines.

5. In order to remain on a dividend paying basis, it is imperative that most of the two-track lines either build additional tracks, or control the electric railroads that parallel them.

6. Believing that ultimately all of the traffic will be done by electricity, it is imperative that the managers of steam roads keep in touch with electrical progress.

\section{Discussion.}

Vice-President Anthony :-I think it has not been customary to discuss an inaugural address, but the nature of this one is such, that doubtless some would like to comment upon it, and I understand that Dr. Duncan wishes you to express your minds freely. The paper is open for discussion.

Mr. Steinmetz:-While I shall not be able to discuss, and still less to criticise this paper, I desire to add a few remarks in connection with one point that has been brought out by Dr. Duncan, namely, the different methods of operating electric railway motors.

There are mentioned:

1st. The continuous current system.

2nd. The continuous current motor operated from an alternating main line by means of rotary converters.

3rd. The alternating current motor.

I think it may be of some interest to investigate the limits of application of these different systems, and find out in which case the one, and in which case the other is preferable.

All electric roads, as far as they are in operation to-day, or as we expect to see them introduced in the near future, belong under the following classes:

1st. Surface roads in the interior of cities.-On these roads the continuous current railway motor with overhead trolley and ground return, operating at a potential of 500 to 600 volts, is used practically without any exception. Only very few roads use either an underground conduit or a double trolley. On city surface roads there is at present no hope of seeing the continuous current motor replaced by any other method of electric propulsion, since the continuous current motor has proved itself entirely satisfactory under the conditions of such a road, and the distances are such that they can easily be reached by 550 volts, or a three-wire system with 1,100 volts between the outside wires. The double 